\title{
Role of creatine supplementation on exercise-induced cardiovascular function and oxidative stress
}

\author{
Michael I.C. Kingsley, ${ }^{1, *}$ Daniel Cunningham, ${ }^{1}$ Laura Mason, ${ }^{1}$ Liam P. Kilduff ${ }^{1}$ and Jane McEneny ${ }^{2}$ \\ ${ }^{1}$ Swansea University; Swansea, UK; ${ }^{2}$ Queen's University Belfast; Nutrition and Metabolism Group; Belfast, UK
}

Key words: creatine monohydrate, lipid peroxidation, hydroperoxides, conjugated diene, antioxidant vitamins

Many degenerative diseases are associated with increased oxidative stress. Creatine has the potential to act as an indirect and direct antioxidant; however, limited data exist to evaluate the antioxidant capabilities of creatine supplementation within in vivo human systems. This study aimed to investigate the effects of oral creatine supplementation on markers of oxidative stress and antioxidant defenses following exhaustive cycling exercise. Following preliminary testing and two additional familiarization sessions, 18 active males repeated two exhaustive incremental cycling trials (T1 and T2) separated by exactly 7 days. The subjects were assigned, in a double-blind manner, to receive either $20 \mathrm{~g}$ of creatine $(\mathrm{Cr})$ or a placebo $(\mathrm{P})$ for the 5 days preceding $\mathrm{T} 2$. Breath-by-breath respiratory data and heart rate were continually recorded throughout the exercise protocol and blood samples were obtained at rest (preexercise), at the end of exercise (postexercise), and the day following exercise (post $24 \mathrm{~h}$ ). Serum hypdroperoxide concentrations were elevated at postexercise by $17 \pm 5 \%$ above preexercise values $(\mathrm{p}=0.030)$. However, supplementation did not influence lipid peroxidation (serum hypdroperoxide concentrations), resistance of low density lipoprotein to oxidative stress $\left(t_{1 / 2 \max }\right.$ LDL oxidation) and plasma concentrations of non-enzymatic antioxidants (retinol, $\alpha$-carotene, $\beta$-carotene, $\alpha$-tocopherol, $\gamma$-tocopherol, lycopene and vitamin $C)$. Heart rate and oxygen uptake responses to exercise were not affected by supplementation. These findings suggest that short-term creatine supplementation does not enhance non-enzymatic antioxidant defence or protect against lipid peroxidation induced by exhaustive cycling in healthy males.

\section{Introduction}

Creatine monohydrate has become a popular supplement, which is reputed to elevate intramuscular high-energy phosphates and

*Correspondence to: Michael I.C. Kingsley; Sport and Exercise Science Research Centre; Swansea University; Vivian Tower; Singleton Park; Swansea SA2 8PP UK; Tel.: +44.1792.513310; Fax: +44.1792.513171; Email: M.I.C.Kingsley@ Swansea.ac.uk

Submitted: 06/26/09; Revised: 07/02/09; Accepted: 07/03/09

Previously published online as an Oxidative Medicine and Cellular Longevity E-publication:

http://www.landesbioscience.com/journals/oximed/article/9415 thereby act as a temporal energy buffer to allow more work to be completed during high-intensity exercise. ${ }^{1}$ Creatine is a nitrogenous organic acid that is endogenously synthesized, predominantly in the liver, from glycine, arganine and methionine. Oral consumption of creatine monohydrate has been demonstrated to increase plasma creatine concentrations ${ }^{2}$ and enhance total creatine concentrations, ${ }^{3}$ which is mostly stored as creatine phosphate $(\mathrm{CrP})$ within skeletal muscles. Consequently, creatine monohydrate supplementation has the potential to improve performance during high-intensity exercise.

In addition to its ergogenic properties, creatine might augment cellular energy supply and attenuate the loss of cellular $\mathrm{Ca}^{2+}$ homeostasis that has been associated with a range of disease populations. ${ }^{4}$ As the accumulation of intracellular $\mathrm{Ca}^{2+}$ has been widely implicated in the formation of reactive oxygen species (ROS) and oxidative damage, ${ }^{5}$ creatine supplementation has the potential to improve $\mathrm{Ca}^{2+}$ homeostasis, reduce $\mathrm{ROS}$ production and lessen oxidative damage. Lawler et al. ${ }^{6}$ were the first to report direct antioxidant properties of creatine. In a series of highly controlled in-vitro studies, these authors demonstrated that creatine was effective in scavenging a range of radicals, including superoxide anion. More recently, exogenous creatine has been demonstrated to scavenge ROS (including hydroxyl radical) as well as reactive nitrogen species in cultured human cells. ${ }^{7}$

There is a growing body of evidence to suggest that creatine supplementation might be beneficial in the prevention and/or treatment of a number of neuromuscular and cardiovascular diseases, for which oxidative stress has been consistently associated. For example, creatine has been demonstrated to improve a variety of outcome measures in animal models of neurodegenerative diseases, such as Huntington's disease, ${ }^{8}$ Parkinson's disease, ${ }^{9}$ amyotrophic lateral sclerosis ${ }^{10,11}$ and other metabolic disorders. ${ }^{12}$ Also, pretreatment with creatine has been shown to protect against ischemic injury in rodent models of stroke ${ }^{13,14}$ and creatine supplementation is an effective adjunct therapy in the protection of cardiac function and antioxidant defences in ovariectomized hamsters. ${ }^{15}$

Oxidative stress within the mitochondrial has been associated with aging, where oxidized nucleotides have been demonstrated to accumulate in the brain and muscle with age. ${ }^{16}$ Additionally, several studies have linked aging with reductions in the mRNA of genes 
associated with mitochondrial structure and function in skeletal muscle and the accumulation of mitochondrial DNA mutations. ${ }^{17}$ Consequently, mitochondrial dysfunction has been implicated in a downward spiral, whereby elevated ROS production causes further mitochondrial damage, mitochondrial dysfunction and increased oxidative stress.

Although a small number of reports, mainly anecdotal in nature, suggest that creatine supplementation has the potential to reduce oxidative stress in diseased populations, ${ }^{18,19}$ the individualized nature of these degenerative diseases makes long-term randomized controlled clinical trials difficult to perform. Consequently, the efficacy of creatine in reducing oxidative stress in humans is unclear. It has been estimated that approximately $2-5 \%$ of the oxygen flux through the mitochondria is not completely reduced to water and generates $\mathrm{ROS},{ }^{20}$ such as superoxide anions and hydroxyl radicals. Under normal resting conditions, elaborate antioxidant defences are able to prevent oxidative damage to biological molecules including lipids, amino acids and nucleotides. $^{21}$ Exercise provoking large increases in whole-body oxygen uptake has the potential to generate ROS (particularly superoxide anions) through the reperfusion of hypoxic tissues in addition to ROS produced through the elevated mitochondrial oxygen flux. Therefore, strenuous concentric muscle activity could increase ROS production, overwhelm normal antioxidant defences, and induce oxidative stress; indeed, exhaustive cycling has been demonstrated to elevate measurements of ROS and lipid peroxidation in apparently healthy humans. ${ }^{22}$

Creatine has potential antioxidant properties (direct and indirect) and has been shown to reduce free radical production and oxidative stress in various animal models of disease; however, limited in-vivo data exists to evaluate the effects of oral creatine monohydrate supplementation on oxidative stress in humans. Therefore, the purpose of the current study was to investigate the proposed antioxidant effects of short-term creatine monohydrate supplementation on antioxidant defences and oxidative stress following exhaustive cycling exercise.

\section{Results}

The environmental conditions were similar during all trials, ambient temperature being $21.8 \pm 0.1$ and $21.9 \pm 0.2^{\circ} \mathrm{C}$, barometric pressure $766 \pm 1$ and $766 \pm 2 \mathrm{mmHg}$, and humidity $45.2 \pm 1.8$ and $44.3 \pm 1.9 \%$, for $\mathrm{T} 1$ and $\mathrm{T} 2$ respectively. The calculated daily diet comprised of $8.9 \pm 0.3 \mathrm{MJ} \cdot \mathrm{d}^{-1}$, of which $45 \pm 2,32 \pm 2,17 \pm 1$ and $6 \pm 3 \%$ of energy intake was obtained from carbohydrates, fat, protein and alcohol, respectively. No differences were identified between groups or trials for calculated antioxidant vitamin intakes (Vitamin A: $528 \pm 2.6 \mu \mathrm{g} \cdot \mathrm{d}^{-1}$; Vitamin C: $47 \pm 6 \mathrm{mg} \cdot \mathrm{d}^{-1}$; Vitamin E: $\left.6.1 \pm 0.5 \mathrm{mg} \cdot \mathrm{d}^{-1}\right)$.

Peak exercising heart rate and whole-body oxygen uptake were similar during all trials (Table 1), being $194 \pm 1$ beats $\min ^{-1}$ and $3.97 \pm 0.07 \mathrm{~L} \cdot \mathrm{min}^{-1}$, respectively. Net whole-body oxygen uptake during exercise $(55.5 \pm 2.1 \mathrm{~L})$ was similar between supplementation groups and did not change following supplementation (Table 1).

Supplementation did not influence changes in plasma volume (trial $\mathrm{x}$ timing $\mathrm{x}$ group effect, $\mathrm{p}=0.359$ ) and these values were similar between trials (trial effect, $\mathrm{p}=0.146$ ), being $-9.7 \pm 0.8 \%$

\begin{tabular}{|c|c|c|c|c|c|}
\hline \multirow[t]{2}{*}{ Table 1} & \multicolumn{5}{|c|}{$\begin{array}{l}\text { Heart rate and oxygen uptake responses to } \\
\text { exhaustive exercise before (Trial 1) and after } \\
\text { (Trial 2) supplementation with creatine and } \\
\text { placebo }\end{array}$} \\
\hline & & & Trial 1 & Trial 2 & $\begin{array}{l}\text { Effect: P } \\
\text { interaction, } \\
\text { trial }\end{array}$ \\
\hline \multicolumn{2}{|c|}{$\begin{array}{l}\text { Peak Heart Rate } \\
\text { (beats } \cdot \mathrm{min}^{-1} \text { ) }\end{array}$} & $\begin{array}{c}\mathrm{Cr} \\
\mathrm{P}\end{array}$ & $\begin{array}{l}195 \pm 3 \\
193 \pm 2\end{array}$ & $\begin{array}{l}194 \pm 3 \\
192 \pm 1\end{array}$ & $\begin{array}{l}0.719 \\
0.523\end{array}$ \\
\hline \multicolumn{2}{|c|}{$\begin{array}{l}\text { Peak Oxygen Uptake } \\
\left(L \cdot \mathrm{min}^{-1}\right)\end{array}$} & $\begin{array}{l}\mathrm{Cr} \\
\mathrm{P}\end{array}$ & $\begin{array}{l}3.92 \pm 0.15 \\
4.01 \pm 0.14\end{array}$ & $\begin{array}{l}3.83 \pm 0.13 \\
4.02 \pm 0.18\end{array}$ & $\begin{array}{l}0.739 \\
0.399\end{array}$ \\
\hline \multicolumn{2}{|c|}{$\begin{array}{l}\text { Net Oxygen Uptake } \\
\text { (L) }\end{array}$} & $\begin{array}{c}\mathrm{Cr} \\
\mathrm{P}\end{array}$ & $\begin{array}{l}52.22 \pm 3.28 \\
58.86 \pm 4.81\end{array}$ & $\begin{array}{l}51.46 \pm 3.18 \\
59.66 \pm 4.77\end{array}$ & $\begin{array}{l}0.971 \\
0.145\end{array}$ \\
\hline
\end{tabular}

Values are last minute values; presented as mean \pm SEM $(N=9)$. Definitions: $\mathrm{Cr}$, Creatine group; $P$, Placebo group. Effects present $p$-values for supplementation group $x$ trial interaction effect and trial effect.

from preexercise values at postexercise and returning to preexercise values at post $24 \mathrm{~h}(1.6 \pm 1.3 \%)$.

Blood lactate concentrations were similarly elevated from preexercise $\left(1.12 \pm 0.06 \mathrm{mmol} \cdot \mathrm{L}^{-1}\right)$ at postexhaustion $(8.31 \pm$ $\left.0.21 \mathrm{mmol} \cdot \mathrm{L}^{-1}\right)$ and postexercise $\left(4.98 \pm 0.20 \mathrm{mmol} \cdot \mathrm{L}^{-1}\right)$ during all trials $(\mathrm{p}<0.001)$ (Table 2$)$. Blood glucose concentrations were not significantly different for preexercise, postexhaustion, postexercise and post $24 \mathrm{~h}$, being $4.17 \pm 0.09,4.35 \pm 0.07$ and 4.32 $\pm 0.07 \mathrm{mmol} \cdot \mathrm{L}^{-1}$, respectively, for all trials (Table 2 ).

Exercise did not change $t_{1 / 2 \max }$ LDL oxidation (time of sample effect, $p=0.502$ ) and supplementation did not influence the pattern of these values (trial $\mathrm{x}$ timing of sample $\mathrm{x}$ group effect, $\mathrm{p}=0.331$ ), with preexercise, postexercise and post $24 \mathrm{~h}$ values being $97.5 \pm 3.9,96.6 \pm 3.8,96.1 \pm 4.3 \mathrm{~min}$, respectively (Table 2).

Serum hypdroperoxide concentrations were elevated at postexercise by $17 \pm 5 \%$ above preexercise values (time of sample effect, $\mathrm{p}=0.030$ ) in all trials (Fig. 1). The three-way interaction effect was not significant (trial $x$ timing of sample $x$ group effect, $p$ $=0.205$ ) and no difference existed between trials (trial effect, $\mathrm{p}=0.959)$.

Supplementation did not influence the pattern of response in any of the measured antioxidant vitamins (trial $x$ timing of sample $\mathrm{x}$ group effect, $\mathrm{p} \geq 0.176$ ). Exercise elevated plasma concentrations of retinol by $7.2 \pm 3.0 \%$ (time of sample effect, $\mathrm{p}=0.015)$. Plasma concentrations of $\alpha$-carotene, $\beta$-carotene, $\alpha$-tocopherol, $\gamma$-tocopherol, lycopene and vitamin $C$ were similar throughout the duration of each trial and were not significantly different between trials (time of sample effect, $\mathrm{p} \geq 0.078$ ) (Table 3).

\section{Discussion}

The main findings of this study were that creatine supplementation (20 g. $\mathrm{d}^{-1}$ of creatine administered for $5 \mathrm{~d}$ ) was not effective in attenuating oxidative stress, did not influence the concentrations of non-enzymatic antioxidant vitamins, and did not alter the susceptibility of LDL particles to oxidative stress in previously familiarized healthy individuals. 
Table 2 Conjugated diene lag times and blood concentrations of lactate and glucose before (trial 1) and after (trial 2) supplementation with creatine $(\mathrm{Cr})$ and placebo $(\mathrm{P})$

\begin{tabular}{|c|c|c|c|c|c|c|c|c|c|c|}
\hline & & $\begin{array}{c}\text { Trial } 1 \\
\text { Preexercise }\end{array}$ & $\begin{array}{c}\text { Trial } 1 \\
\text { Postexhaustion }\end{array}$ & $\begin{array}{c}\text { Trial } 1 \\
\text { Postexercise }\end{array}$ & $\begin{array}{c}\text { Trial } 1 \\
\text { Post24 h }\end{array}$ & $\begin{array}{c}\text { Trial } 2 \\
\text { Preexercise }\end{array}$ & $\begin{array}{c}\text { Trial } 2 \\
\text { Postexhaustion }\end{array}$ & $\begin{array}{c}\text { Trial } 2 \\
\text { Postexercise }\end{array}$ & $\begin{array}{c}\text { Trial } 2 \\
\text { Post24 h }\end{array}$ & $\begin{array}{c}\text { Effect: P } \\
\text { interaction, } \\
\text { timing }\end{array}$ \\
\hline $\begin{array}{l}\text { Lactate } \\
\left(\mathrm{mmol} \cdot \mathrm{L}^{-1}\right)\end{array}$ & $\begin{array}{l}\mathrm{Cr} \\
\mathrm{P}\end{array}$ & $\begin{array}{l}1.02 \pm 0.08 \\
1.08 \pm 0.14\end{array}$ & $\begin{array}{l}8.21 \pm 0.52 \\
8.25 \pm 0.42\end{array}$ & $\begin{array}{l}5.00 \pm 0 \\
4.90 \pm 0\end{array}$ & $\begin{array}{l}0.89 \pm \\
1.29 \pm\end{array}$ & & & & & \\
\hline $\begin{array}{l}\text { Glucose } \\
\left(\mathrm{mmol} \cdot \mathrm{L}^{-1}\right)\end{array}$ & $\begin{array}{l}\mathrm{Cr} \\
\mathrm{P}\end{array}$ & $\begin{array}{l}4.14 \pm 0.17 \\
4.20 \pm 0.05\end{array}$ & $\begin{array}{l}4.18 \pm 0.14 \\
4.58 \pm 0.11\end{array}$ & $\begin{array}{l}4.44 \pm 0.25 \\
4.74 \pm 0.18\end{array}$ & $\begin{array}{l}4.09 \pm 0.08 \\
4.27 \pm 0.11\end{array}$ & $\begin{array}{l}3.85 \pm 0.19 \\
4.48 \pm 0.21\end{array}$ & $\begin{array}{l}4.25 \pm 0.12 \\
4.40 \pm 0.16\end{array}$ & $\begin{array}{l}4.44 \pm 0.26 \\
4.48 \pm 0.15\end{array}$ & $\begin{array}{l}4.29 \pm 0.10 \\
4.63 \pm 0.21\end{array}$ & $\begin{array}{l}0.132 \\
0.059\end{array}$ \\
\hline
\end{tabular}

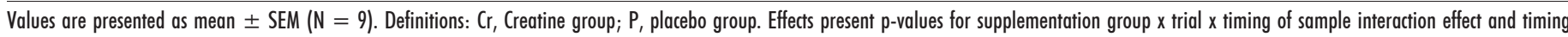
effect.

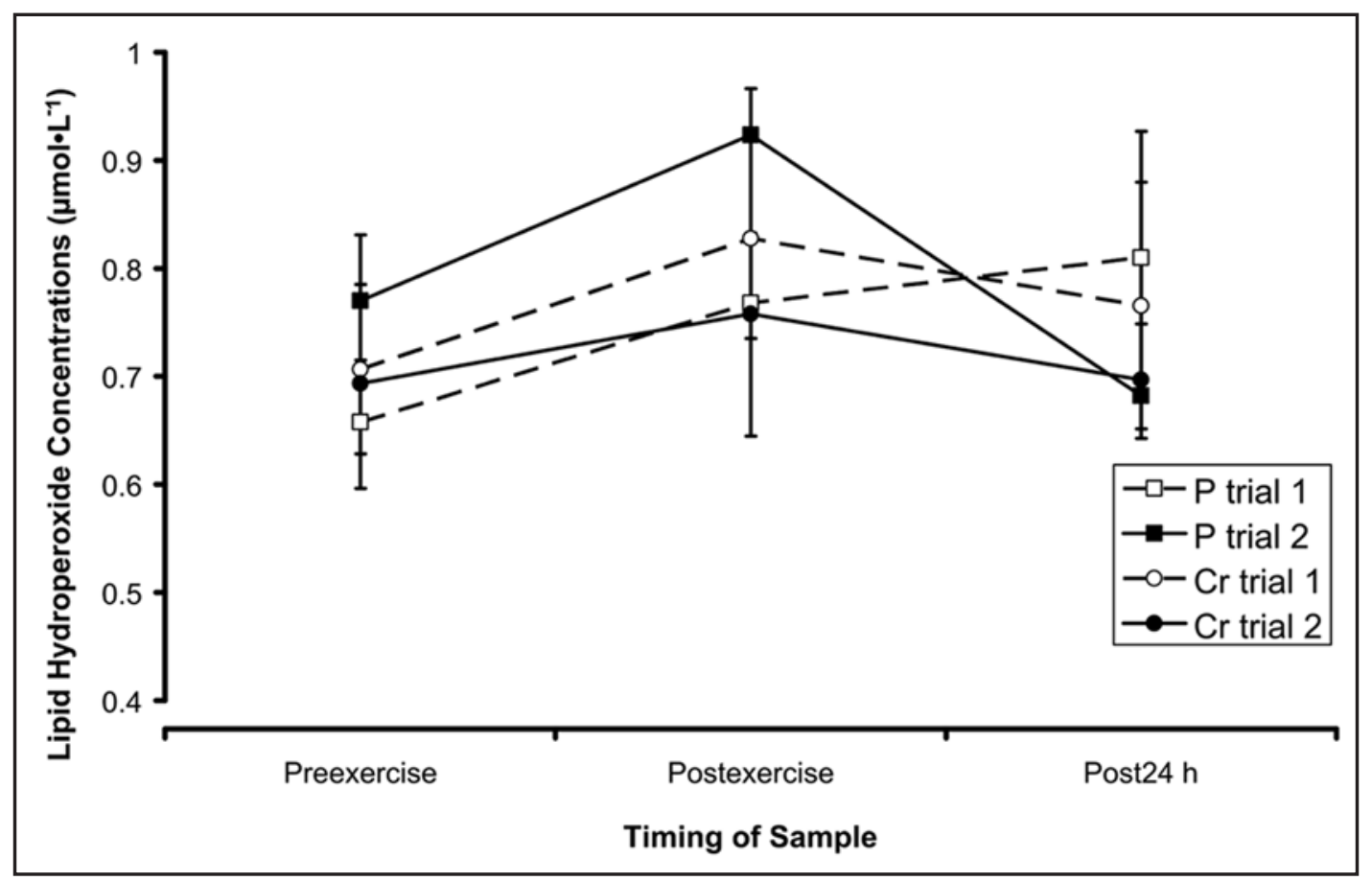

Figure 1. Exercise-induced lipid peroxidation as measured by serum hydroperoxide concentrations. Exhaustive cycling caused increases in lipid peroxidation (time of sample effect, $p=0.030$ ), with serum hydroperoxide concentrations being elevated after exercise (ost-exercise) when compared with values before (Pre-exercise) and 24 hours after exercise (Post-24 h). The pattern of response was similar following supplementation with creatine $(\mathrm{Cr})$ and placebo $(\mathrm{P})$ (trial $x$ timing of sample $x$ group effect, $\mathrm{p}=0.205)$. Values represent mean $\pm \operatorname{SEM}(\mathrm{N}=9$ ).

The cycling protocol increased lipid peroxidation above preexercise values, as measured by increased postexercise serum hypdroperoxide concentrations. The relative change in lipid peroxidation $(17 \pm 5 \%)$ was less than we previously reported after intermittent running, where increases of $24 \pm 5 \%$ were measured. ${ }^{23}$ Exhaustive cycling does not involve significant amounts of eccentric muscle activity and structural muscle damage; therefore, unlike intermittent running, cycling does not lead to inflammationmediated free radical production that follows structural muscle damage. ${ }^{24}$ Consequently, during the current study, it is likely that increased mitochondrial oxygen flux led to elevated ROS production that overwhelmed the antioxidant defences and caused oxidative stress. In support of this premise, incremental cycling has previously been demonstrated to increase the intensity of the electron spin resonance (ESR) signal in the plasma of healthy young subjects. ${ }^{22}$ These authors suggested that the enhanced postexercise ESR signal reflected an increase in the concentration of alkoxyl radicals formed as a consequence of primary ROS (such as superoxide anion and hydroxyl radicals) attack on membrane phospholipids.

The amount of external work undertaken during the individualised exhaustive protocol was matched during T1 and T2; furthermore, heart rate, oxygen uptake and blood lactate concentrations reached similar peak values at the end of exercise during all trials suggesting that the protocol challenged all subjects to an equal extent. Net whole-body oxygen uptake was similar between groups and trials (Table 2). Assuming that the rate of mitochondrial ROS production remained approximately constant 
Table 3 Plasma antioxidant vitamin concentrations before (trial 1) and after (trial 2) supplementation with creatine $(\mathrm{Cr})$ and placebo $(\mathrm{P})$

\begin{tabular}{|c|c|c|c|c|c|c|c|c|}
\hline & & $\begin{array}{c}\text { Trial } 1 \\
\text { Preexercise }\end{array}$ & $\begin{array}{c}\text { Trial } 1 \\
\text { Postexercise }\end{array}$ & $\begin{array}{c}\text { Trial } 1 \\
\text { Post24 h }\end{array}$ & $\begin{array}{c}\text { Trial } 2 \\
\text { Preexercise }\end{array}$ & $\begin{array}{c}\text { Trial } 2 \\
\text { Postexercise }\end{array}$ & $\begin{array}{c}\text { Trial } 2 \\
\text { Post24 h i }\end{array}$ & $\begin{array}{c}\text { Effect } P \\
\text { interaction, timing }\end{array}$ \\
\hline $\begin{array}{l}\text { retinol } \\
\left(\mu \mathrm{mol} \cdot \mathrm{L}^{-1}\right)\end{array}$ & $\begin{array}{l}\mathrm{Cr} \\
\mathrm{P}\end{array}$ & $\begin{array}{l}2.1 \pm 0.2 \\
2.3 \pm 0.3\end{array}$ & $\begin{array}{l}2.2 \pm 0.2 \\
2.3 \pm 0.3\end{array}$ & $\begin{array}{l}2.3 \pm 0.2 \\
2.4 \pm 0.2\end{array}$ & $\begin{array}{l}2.1 \pm 0.2 \\
2.2 \pm 0.3\end{array}$ & $\begin{array}{l}2.3 \pm 0.2 \\
2.5 \pm 0.3\end{array}$ & $\begin{array}{l}2.3 \pm 0.2 \\
2.2 \pm 0.2\end{array}$ & $\begin{array}{l}0.482 \\
0.015\end{array}$ \\
\hline $\begin{array}{l}\alpha \text {-carotene } \\
\left(\mu \mathrm{mol} \cdot \mathrm{L}^{-1}\right)\end{array}$ & $\begin{array}{l}\mathrm{Cr} \\
\mathrm{P}\end{array}$ & $\begin{array}{l}0.20 \pm 0.05 \\
0.15 \pm 0.02\end{array}$ & $\begin{array}{l}0.22 \pm 0.04 \\
0.17 \pm 0.01\end{array}$ & $\begin{array}{l}0.21 \pm 0.04 \\
0.16 \pm 0.02\end{array}$ & $\begin{array}{l}0.18 \pm 0.04 \\
0.15 \pm 0.02\end{array}$ & $\begin{array}{l}0.16 \pm 0.04 \\
0.16 \pm 0.02\end{array}$ & $\begin{array}{l}0.17 \pm 0.03 \\
0.15 \pm 0.02\end{array}$ & $\begin{array}{l}0.401 \\
0.870\end{array}$ \\
\hline $\begin{array}{l}\beta \text {-carotene } \\
\left(\mu \mathrm{mol} \cdot \mathrm{L}^{-1}\right)\end{array}$ & $\begin{array}{c}\mathrm{Cr} \\
\mathrm{P}\end{array}$ & $\begin{array}{l}0.61 \pm 0.15 \\
0.42 \pm 0.07\end{array}$ & $\begin{array}{l}0.70 \pm 0.13 \\
0.46 \pm 0.07\end{array}$ & $\begin{array}{l}0.70 \pm 0.18 \\
0.47 \pm 0.12\end{array}$ & $\begin{array}{l}0.55 \pm 0.12 \\
0.43 \pm 0.07\end{array}$ & $\begin{array}{l}0.49 \pm 0.12 \\
0.53 \pm 0.14\end{array}$ & $\begin{array}{l}0.47 \pm 0.10 \\
0.49 \pm 0.11\end{array}$ & $\begin{array}{l}0.176 \\
0.563\end{array}$ \\
\hline $\begin{array}{l}\alpha \text {-tocopherol } \\
\left(\mu \mathrm{mol} \cdot \mathrm{L}^{-1}\right)\end{array}$ & $\begin{array}{l}\mathrm{Cr} \\
\mathrm{P}\end{array}$ & $\begin{array}{l}28.3 \pm 1.8 \\
29.5 \pm 2.7\end{array}$ & $\begin{array}{l}29.1 \pm 2.2 \\
31.0 \pm 2.6\end{array}$ & $\begin{array}{l}29.9 \pm 2.5 \\
31.2 \pm 2.6\end{array}$ & $\begin{array}{l}28.7 \pm 1.6 \\
29.5 \pm 2.6\end{array}$ & $\begin{array}{l}28.2 \pm 1.8 \\
31.0 \pm 2.6\end{array}$ & $\begin{array}{l}28.2 \pm 1.6 \\
31.2 \pm 2.6\end{array}$ & $\begin{array}{l}0.876 \\
0.078\end{array}$ \\
\hline $\begin{array}{l}\gamma \text {-tocopherol } \\
\left(\mu \mathrm{mol} \cdot \mathrm{L}^{-1}\right)\end{array}$ & $\begin{array}{l}\mathrm{Cr} \\
\mathrm{P}\end{array}$ & $\begin{array}{l}1.4 \pm 0.1 \\
1.5 \pm 0.2\end{array}$ & $\begin{array}{l}1.3 \pm 0.1 \\
1.5 \pm 0.1\end{array}$ & $\begin{array}{l}1.4 \pm 0.2 \\
1.5 \pm 0.1\end{array}$ & $\begin{array}{l}1.2 \pm 0.1 \\
1.5 \pm 0.2\end{array}$ & $\begin{array}{l}1.1 \pm 0.1 \\
1.7 \pm 0.2\end{array}$ & $\begin{array}{l}1.2 \pm 0.1 \\
1.7 \pm 0.2\end{array}$ & $\begin{array}{l}0.419 \\
0.481\end{array}$ \\
\hline $\begin{array}{l}\text { lycopene } \\
\text { (umol. } \mathrm{L}^{-1} \text { ) }\end{array}$ & $\begin{array}{l}\mathrm{Cr} \\
\mathrm{P}\end{array}$ & $\begin{array}{l}1.4 \pm 0.3 \\
1.3 \pm 0.5\end{array}$ & $\begin{array}{l}2.0 \pm 0.4 \\
1.5 \pm 0.3\end{array}$ & $\begin{array}{l}1.9 \pm 0.5 \\
1.2 \pm 0.1\end{array}$ & $\begin{array}{l}1.5 \pm 0.5 \\
1.0 \pm 0.1\end{array}$ & $\begin{array}{l}1.3 \pm 0.3 \\
1.8 \pm 0.4\end{array}$ & $\begin{array}{l}1.2 \pm 0.3 \\
1.0 \pm 0.2\end{array}$ & $\begin{array}{l}0.514 \\
0.087\end{array}$ \\
\hline $\begin{array}{l}\text { vitamin } C \\
\left(\mu \mathrm{mol} \cdot \mathrm{L}^{-1}\right)\end{array}$ & $\begin{array}{c}\mathrm{Cr} \\
\mathrm{P}\end{array}$ & $\begin{array}{l}45.0 \pm 3.9 \\
48.1 \pm 2.9\end{array}$ & $\begin{array}{l}48.1 \pm 4.5 \\
43.0 \pm 4.3\end{array}$ & $\begin{array}{l}42.7 \pm 6.0 \\
47.4 \pm 4.6\end{array}$ & $\begin{array}{l}49.7 \pm 4.9 \\
41.7 \pm 3.5\end{array}$ & $\begin{array}{l}44.5 \pm 4.1 \\
42.3 \pm 5.1\end{array}$ & $\begin{array}{l}47.1 \pm 5.6 \\
44.1 \pm 5.6\end{array}$ & $\begin{array}{l}0.631 \\
0.230\end{array}$ \\
\hline
\end{tabular}

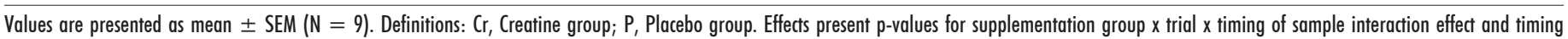
effect.

for all individuals, the exercise protocol was effective in producing similar amounts of ROS during T1 and T2. Consequently, this repeated measures design was successful in challenging the antioxidant defences of all subjects to a comparable extent during the main exercise trials.

The finding that creatine supplementation did not influence oxygen uptake during exhaustive exercise is in agreement with previous literature. ${ }^{25,26}$ Further evidence to suggest that cardiopulmonary function during exhaustive exercise was unaffected by creatine supplementation was provided by the similarity in heart rate and net oxygen uptake responses before and after supplementation. In support of this conclusion, most previous studies that evaluate similar outcomes have failed to identify any effect of creatine supplementation on aerobic capacity in healthy ${ }^{27-31}$ and diseased populations. ${ }^{32-34}$ Nevertheless, some studies have demonstrated that creatine supplementation can influence other parameters that have the potential to contribute to improved endurance performance. For example, creatine-induced hyperhydration has been shown to attenuate heart rate responses to prolonged exercise in the heat ${ }^{26}$ and creatine supplementation has been demonstrated to increase lactate threshold, ${ }^{27}$ improve submaximal effeciency, ${ }^{31}$ and enhance peak work capacity at fatigue during discontinuous exercise in elderly participants. ${ }^{35}$

It has been repeatedly demonstrated that the current creatine monohydrate supplementation regime is effective in increasing circulatory creatine concentrations $s^{2,3}$ and pharmacokinetic analysis of plasma creatine concentrations following a 5-g oral bolus of creatine monohydrate showed that plasma creatine decayed with a half-life of approximately $2 \mathrm{~h} .{ }^{36}$ Therefore, it is probable that the current supplementation protocol elevated plasma and intramuscular creatine concentrations.

Calculated intakes of the main dietary antioxidant vitamins were similar during all trials and supplementation had no effect on plasma concentrations of the antioxidant vitamins (retinol, $\alpha$-carotene, $\beta$-carotene, $\alpha$-tocopherol, $\gamma$-tocopherol, and lycopene, and vitamin $\mathrm{C}$ ). In addition, the two main exercise trials were completed within $7 \mathrm{~d}$; therefore, it is likely that the enzymatic antioxidant defences remained similar for each individual during both main exercise trials. As the enzymatic and non-enzymatic vitamin antioxidant defence were comparable between exercise trials, this repeated measure design was suitable to assess the influence of short-term oral creatine supplementation as an in-vivo antioxidant.

Supplementation did not influence the pattern of response in serum hydroperoxide concentrations (trial $\mathrm{x}$ timing of sample $\mathrm{x}$ group effect, $\mathrm{p}=0.205)$. Although there was a tendency for mean serum hydroperoxide concentrations to be reduced following supplementation with creatine (Fig. 1), creatine supplementation did not significantly influence lipid peroxidation following exhaustive cycling. Therefore, the current finding does not confirm previous in-vitro data showing that creatine acts a direct antioxidant. ${ }^{6,7}$ Lawler et al. ${ }^{6}$ were the first to report that creatine effectively quenches superoxide anions and other aqueous radical species in highly controlled cell-free environments. Later, intracellular creatine was also shown to act as a direct antioxidant by scavenging ROS (particularly hydroxyl radicals) in cultured cells. ${ }^{7}$ Mitochondrial ROS production (including superoxide anions and hydroxyl radicals) is likely to be the primary source of free radicals during cycling; consequently, it is unclear why the current creatine supplementation regime, which has been previously demonstrated to increase plasma and intramuscular creatine, was ineffective in attenuating lipid peroxidation in the current study.

Differences between in-vivo and in-vitro systems might partially explain the lack of statistical evidence to support an antioxidant effect in the current study. Although the current supplementation regime has been shown to "load" muscle cells to threshold levels, ${ }^{3}$ considerable heterogeneity exists in intramuscular creatine uptake following oral supplementation. It is, therefore, possible that the 
Table 4 Subject characteristics for creatine supplementation group ( $\mathrm{Cr}$ ) and placebo group (P)

\begin{tabular}{lccc}
\hline Characteristic & $\mathbf{C r}(\mathbf{N}=\mathbf{9})$ & $\mathbf{P}(\mathbf{N}=\mathbf{9})$ & $\mathbf{p}$-value \\
Age (dec. years) & $21.7 \pm 0.8$ & $21.2 \pm 0.2$ & 0.638 \\
Mass $(\mathrm{kg})$ & $77.9 \pm 2.8$ & $84.3 \pm 2.5$ & 0.103 \\
Height $(\mathrm{m})$ & $1.77 \pm 0.02$ & $1.77 \pm 0.01$ & 0.956 \\
Body composition (\%BF) & $18.2 \pm 0.8$ & $15.4 \pm 1.0$ & 0.061 \\
Maximal oxygen uptake & $50.8 \pm 1.9$ & $48.0 \pm 1.7$ & 0.290 \\
$\left(\mathrm{ml}^{-1} \mathrm{~kg}^{-1} \cdot \mathrm{min}^{-1}\right)$ & & &
\end{tabular}

Values are mean \pm SEM. p-value calculated using independent sample t-test.

change in intracellular creatine concentrations from $\mathrm{T} 1$ to $\mathrm{T} 2$ in $\mathrm{Cr}$ was insufficient to cause significant differences in lipid peroxidation. This finding suggests that increasing intramuscular creatine in healthy young males does not afford additional protection against oxidative damage derived from strenuous concentric muscle activity.

Supplementation did not influence $t_{1 / 2 \max }$ LDL oxidation (Table 3). As $t_{1 / 2 \max }$ LDL oxidation measures the resistance of LDL particles to oxidation, these data suggest that creatine did not alter the antioxidant defences of LDL particles in healthy young males. Unlike the current data, some recent studies have previously demonstrated that prolonged exercise involving considerable eccentric muscular activity causes significant increases in LDL resistance to peroxidation in healthy males. ${ }^{23,37}$ These equivocal results probably reflect increased mobilisation of antioxidant defences following prolonged exercise that leads to muscle damage and acute inflammation.

Similar doses of creatine have been repeatedly demonstrated to enhance short-term exercise performance in healthy individuals, which has generally been ascribed to enhanced temporal energy buffering through increased intramuscular $\mathrm{CrP}^{1}$ Supplementation did not influence peak values for heart rate, oxygen uptake, and blood glucose and lactate concentrations (Table 3); therefore the metabolic responses to matched exhaustive exercise were not changed by creatine supplementation. Nevertheless, Andrews et al. ${ }^{38}$ showed that creatine supplementation attenuated blood concentrations of lactate and ammonia responses to exhaustive handgrip dynamometry exercise in patients with chronic heart failure. Consequently, creatine supplementation might be more effective in maintaining cellular energy supply in patient populations; thereby, reducing the accumulation of intracellular $\mathrm{Ca}^{2+}$, limiting the formation of reactive oxygen species (ROS) and attenuate oxidative damage. ${ }^{5}$

Although the current data does not support in-vivo antioxidant benefits, mediated by direct or indirect mechanisms, from shortterm creatine supplementation in healthy young males, it remains possible that individuals with diseases that are associated with reduced antioxidant defences and elevated radical production, probably through an impairment in cellular energy metabolism, might benefit from creatine supplementation. Creatine is unique, within the currently available antioxidants, in that it has the potential to reduce ROS production through better maintenance of cellular energetics as well as quench ROS and other radical species. Indeed, oral creatine supplementation has been demonstrated to reduce oxidative stress and prevent paracrystalline inclusions in a patient with mitochondrial dysfunction. ${ }^{19} \mathrm{~A}$ small number of randomised clinical trials have evaluated the effects of short- to moderate-term creatine supplementation in patients with diseases that have been traditionally associated with oxidative stress, such as Huntington's disease, ${ }^{39}$ Parkinson's disease, ${ }^{40-42}$ amyotrophic lateral sclerosis, ${ }^{43-45}$ rheumatoid arthritis, ${ }^{46}$ chronic obstructive pulmonary disease ${ }^{47}$ and congestive heart failure. ${ }^{38}$ Although equivocal, these studies have generally reported small positive effects in a range of outcome measures. Nevertheless, no data from randomised clinical trials are currently available to evaluate the influence of creatine supplementation on oxidative stress in patient populations.

In summary, this is the first study to evaluate the effects of creatine supplementation on acute exercise-derived oxidative stress in healthy young males. Short-term creatine supplementation was ineffective in attenuating oxidative stress (as measured by serum hydroperoxide concentrations) induced by exhaustive cycling; in addition, supplementation did not influence LDL susceptibility to oxidative stress exercise or change plasma concentrations of antioxidant vitamins. Nevertheless, it remains possible that creatine supplementation could benefit patient populations that have increased susceptibility to oxidative stress due to impaired cellular energy metabolism and decreased antioxidant defences.

\section{Methods}

Subjects. Eighteen healthy male volunteers (age: $21.5 \pm 0.4$ years; stature: $1.77 \pm 0.01 \mathrm{~m}$; body mass: $81.1 \pm 2.0 \mathrm{~kg}$; body composition: $16.8 \pm 0.7 \% \mathrm{BF}$ ) were informed about the potential risks of the study and gave written informed consent for their participation in the study, which was approved by a local research ethics committee. No subject had prior history of cardiovascular or respiratory disease and all subjects were non-smokers. Potential subjects attended an interview prior to undertaking the study and were subsequently excluded if they engaged in a structured weight training programme, or had taken creatine or other nutritional supplements in the 8 weeks prior to the study.

Experimental design. Prior to the main exercise trials, all subjects completed three incremental exercise tests (separated by exactly 7 d) in order to ensure that the subjects were fully familiarized and able to repeat the exhaustive exercise protocol. Subjects then performed two main exercise trials, which consisted of incremental cycling that was continued until the individualized predetermined point of exhaustion (determined during the preliminary trials), and separated by exactly $7 \mathrm{~d}$. Two days after completing the first main exercise trial (T1) the subjects were assigned, in a randomised double-blind fashion, to either a creatine $(\mathrm{Cr})$ group or a placebo $(\mathrm{P})$ group and instructed to take supplements for $5 \mathrm{~d}$, which included 4 $\mathrm{d}$ prior to and the day of trial two (T2). The subject characteristics of each group are presented in Table 4. The $\mathrm{Cr}$ group ingested 22.8 $\mathrm{g} \cdot \mathrm{d}^{-1} \mathrm{Cr} \cdot \mathrm{H}_{2} \mathrm{O}$ (equivalent to $5 \mathrm{~g} \mathrm{Cr} \times 4$ daily) for $5 \mathrm{~d}$. Each supplement dose consisted of $5.7 \mathrm{~g} \mathrm{Cr} \cdot \mathrm{H}_{2} \mathrm{O}$ and $5 \mathrm{~g}$ of glucose polymer 
dissolved in $500 \mathrm{ml}$ of warm water. This regimen was adopted in light of the work by Harris et al. ${ }^{2}$ who found that this protocol resulted in significant increases in total creatine content of resting quadriceps femoris muscle; in addition, the majority of studies that have shown a direct or indirect increase in total creatine concentration have used similar supplementation regimes. Dissolving creatine in warm water prevented any detectable formation of creatinine, with no parts of the supplement remaining undissolved. The placebo group consumed $40 \mathrm{~g} \cdot \mathrm{d}^{-1}$ of glucose polymer. Both supplements had similar taste, texture and appearance, and were administered in generic packaging. Subjects were instructed to maintain their normal diet and activity patterns throughout the study. Food was weighed and recorded by the subjects for $2 \mathrm{~d}$ prior to each exercise trial and for $1 \mathrm{~d}$ afterwards. These food records were subsequently analyzed using commercial software (CompEat version v5.8.0; Nutrition Systems, UK). In addition, the subjects were instructed to abstain from strenuous exercise for $3 \mathrm{~d}$ before and $1 \mathrm{~d}$ following each trial. At the completion of the study all subjects gave their verbal assurance that they had complied with all instructions. The experimental design is illustrated in Figure 2.

Preliminary procedures. Subjects were habituated with the exercise protocol on three separate occasions prior to the main exercise trials. After a 5-min warm-up at $60 \mathrm{~W}$ and a 3-min rest period the subjects completed an incremental exercise test on an electromagnetically braked cycle ergometer (Lode Excalibur Sport; Lode, Holland). The work rate began at $60 \mathrm{~W}$ and thereafter increased in $10-\mathrm{W}$ increments every $1 \mathrm{~min}$ until volitional exhaustion, which was defined as an inability to maintain a cadence of 60 rev $\min ^{-1}$ despite verbal encouragement. The time to exhaustion during the preliminary tests were used to determine the exercise time for the main exercise trials; therefore, the individualised exercise protocol was recorded and repeated during both main exercise trials. Heart rate (S810; Polar Electro Oy, Finland) and breath-bybreath respiratory parameters (Oxycon Pro; Jaeger, Germany) were simultaneously recorded throughout exercise. Breath-by-breath oxygen uptake during exercise was used to calculate net oxygen uptake.

During the initial preliminary session, mass (model 712; Seca, Germany) and stature (Portable Stadiometer; Holtain, UK) were measured; additionally, percentage body fat $(\mathrm{BF})$ was determined using bioelectrical impedance analyses (Quadscan; Bodystat, Isle of Man), as previously described. ${ }^{48}$

Main trial procedures. On the day of each main exercise trial the subjects reported to the laboratory at approximately the same time of day $( \pm 1 \mathrm{~h})$ and following an overnight fast. After 5-min of cycling at $60 \mathrm{~W}$ and a 3-min rest period the subjects completed the individualized incremental cycling protocol. Subjects were instructed to pedal at a constant cadence between 65 and 75 rev $\min ^{-1}$. Heart rate (S810; Polar Electro Oy, Finland), and breath-by-breath respiratory parameters (Oxycon Pro; Jaeger, Germany) were simultaneously recorded throughout exercise. Blood samples were taken by venepuncture (Vacutainer system; Becton-Dickinson Ltd., UK) in a seated position from an antecubital vein before exercise (preexercise), 20 min after the completion of exercise (postexercise), and $24 \mathrm{~h}$ after the trial (Post24 h). Additional capillary blood samples were taken immediately after

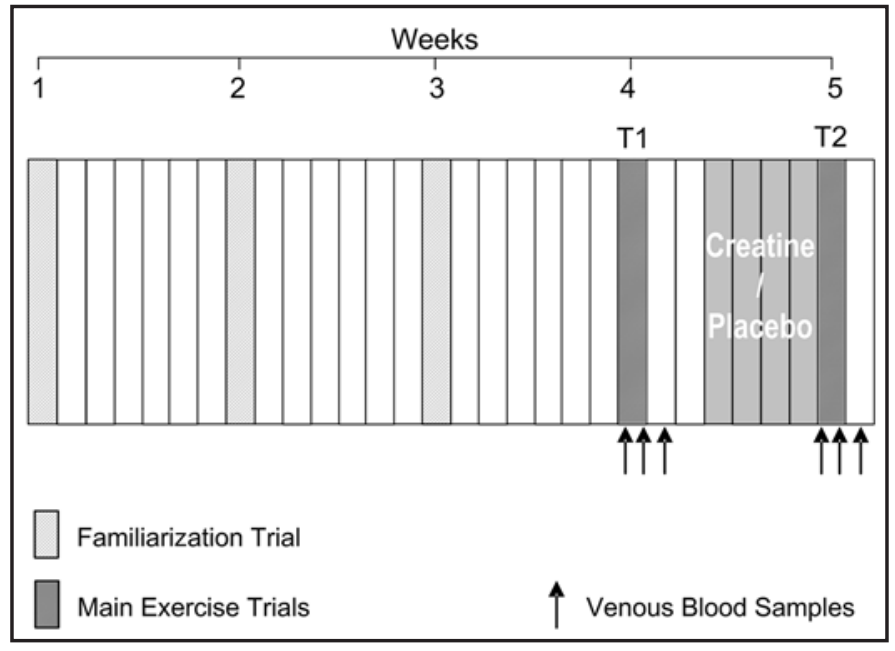

Figure 2. Schematic diagram representing the experimental design that was used to evaluate the role of creatine supplementation on exerciseinduced cardiovascular function and oxidative stress. After repeated familiarization, the subjects performed two main exercise trials that consisted of exhaustive incremental cycling. Two days after completing the first main exercise trial (T1) the subjects were assigned, in a randomised double-blind fashion, to either a creatine $(\mathrm{Cr})$ group or a placebo $(\mathrm{P})$ group and instructed to take supplements for $5 \mathrm{~d}$, which included $4 \mathrm{~d}$ prior to and the day of trial two (T2).

exhaustion (postexhaustion) for the analysis of blood lactate and glucose concentrations. Ambient temperature and humidity were recorded at the beginning and end of exercise (ETHG-912; Oregan Scientific, USA).

Blood sampling and analysis. Venous blood was collected in a $5 \mathrm{~mL}$ container (Becton-Dickinson Ltd., UK) containing the anticoagulant ethylenediamine tetraacetic acid (EDTA). Several small aliquots were removed for the triplicate determination of blood lactate concentration, glucose concentration (YSI 2300, Yellow Springs Instruments, US), hemoglobin concentration (Hemocue Ltd., UK), hematocrit (Micro hematocrit MK IV, Hawksley, UK) and changes in plasma volume were estimated as previously described. ${ }^{49}$ The remaining blood was centrifuged at 3,000 g for 15 min to obtain plasma. An aliquot of plasma $(100 \mu \mathrm{L})$ was added to $900 \mu \mathrm{L}$ of freshly prepared $10 \%$ metaphosphoric acid, mixed and frozen at $-70^{\circ} \mathrm{C}$ for subsequent vitamin $\mathrm{C}$ analysis. The remaining plasma was frozen in aliquots and stored at $-70^{\circ} \mathrm{C}$ prior to subsequent analysis. Two additional $7 \mathrm{~mL}$ blood samples were collected in serum separation tubes (Becton-Dickinson Ltd., UK), left to stand for $15 \mathrm{~min}$ then centrifuged at $3,000 \mathrm{~g}$ for $15 \mathrm{~min}$ to obtain serum. The serum was transferred to appropriate containers and subsequently stored at $-70^{\circ} \mathrm{C}$ prior to analysis.

Serum hydroperoxide concentrations were measured as described in McEneny et al. ${ }^{50}$ Low density lipoprotein was isolated from plasma and oxidised according to the method of McDowell et al. ${ }^{51}$ Subsequently, the production of conjugated dienes was followed in triplicate at $234 \mathrm{~nm}$ (SpectraMax 190; Molecular Devices Corp., US) using the computer software SoftMax Pro Version 3.0 (Molecular Devices Corp., US); the change in absorbance (from baseline to the maximum absorbance following the propagation 


\section{Creatine supplementation and oxidative stress}

phase) was used to quantify conjugated diene concentration, and the time taken to reach half of the maximum oxidation $\left(\mathrm{t}_{1 / 2 \max } \mathrm{LDL}\right.$ oxidation), which directly correlates with conjugated diene lag time, was taken as a measure of the resistance of the particle to oxidation. The duration of the conjugated diene lag time has been shown to correlate with endogenous antioxidants in LDL. ${ }^{52}$ Vitamin C concentrations were determined using a fluorimetric assay using a centrifugal analyser with fluorescence attachment according to the method of Vuilleumier and Keck. ${ }^{53}$ Plasma concentrations of retinol, $\alpha$-carotene, $\beta$-carotene, $\alpha$-tocopherol, $\gamma$-tocopherol and lycopene were measured by high-performance lipid chromatography with electrochemical detection according to the methods of Craft. ${ }^{54}$ The intra-assay coefficient of variance $(\% \mathrm{CV})$ for these assays ranged from 1.4 for $\alpha$-tocopherol to 12.0 for lycopene.

Statistical analysis. Statistical analysis was carried out using SPSS software (version 13.0; SPSS Inc., IL, US). Group data were expressed as mean \pm SEM and statistical significance was set at the $\mathrm{p}<0.05$ level. All data were assessed for normality (ShapiroWilk's test) and data that were not normally distributed (plasma retinol, $\alpha$-tocopherol and lycopene concentrations) were log transformed prior to analyses. Subject characteristics were compared under supplementation groups using independent samples t-tests (Table 1). Environmental conditions were compared using paired samples t-tests. Body composition, heart rate and whole-body oxygen uptake measurements were assessed using mixed-model repeated measures ANOVA (within-subject factors: trials; betweensubject factor: supplementation groups). The remaining data, which contained multiple time points during each trial, were analysed using mixed-model repeated measures ANOVA (within subject factors: trial $\mathrm{x}$ time of sample; between subject factor: group). Mauchly's test was consulted and Greenhouse-Geisser correction was applied if the assumption of sphericity was violated. If a significant $\mathrm{p}$ value was identified for the three-way interaction (group $\mathrm{x}$ trial $\mathrm{x}$ time of sample), the subject groups reacted differently and supplementation was deemed to have had a significant effect. Where a significant $\mathrm{p}$ value was identified for the main effect of time (time of sample), multiple pairwise comparisons were made using Bonferonni confidence interval adjustment.

\section{Acknowledgements}

The authors wish to acknowledge the excellent technical assistance provided by Mrs. Rebecca Dietzig at the University of Wales Swansea and the laboratory staff from Queen's University Belfast.

\section{References}

1. Field M, Clark J, Henderson C, Seymour A, Radda G. Alterations in the myocardial creatine kinase system during chronic anaemic hypoxia. Cardiovasc Res 1994; 28:86-91.

2. Harris RC, Soderlund K, Hultman E. Elevation of creatine in resting and exercised muscle of normal subjects by creatine supplementation. Clin Sci 1992; 83:367-74.

3. Greenhaff PL, Bodin K, Soderlund K, Hultman E. Effect of oral creatine supplementation on skeletal muscle phosphocreatine resynthesis. Am J Physiol Endocrinol Metab 1994; 266:725-30.

4. Raza M, Deshpande LS, Blair RE, Carter DS, Sombati S, DeLorenzo RJ. Aging is associated with elevated intracellular calcium levels and altered calcium homeostatic mechanisms in hippocampal neurons. Neurosci Lett 2007; 418:77-81.

5. Lin MT, Beal MF. Mitochondrial dysfunction and oxidative stress in neurodegenerative diseases. Nature 2006; 443:787-95.

6. Lawler JM, Barnes WS, Wu G, Song W, Demaree S. Direct Antioxidant Properties of Creatine. Biochem Biophys Res Comm 2002; 290:47-52.
7. Sestili P, Martinelli C, Bravi G, Piccoli G, Curci R, Battistelli M, et al. Creatine supplementation affords cytoprotection in oxidatively injured cultured mammalian cells via direct antioxidant activity. Free Rad Biol Med 2006; 40:837-49.

8. Ferrante RJ, Andreassen OA, Jenkins BG, Dedeoglu A, Kuemmerle S, Kubilus JK, et al. Neuroprotective Effects of Creatine in a Transgenic Mouse Model of Huntington's Disease. J Neurosci 2000; 20:4389-97.

9. Matthews RT, Ferrante RJ, Klivenyi P, Yang L, Klein AM, Mueller G, et al. Creatine and Cyclocreatine Attenuate MPTP Neurotoxicity. Exp Neurol 1999; 157:142-9.

10. Klivenyi P, Ferrante RJ, Matthews RT, Bogdanov MB, Klein AM, Andreassen OA, et al Neuroprotective effects of creatine in a transgenic animal model of amyotrophic lateral sclerosis. Nat Med 1999; 5:347-50.

11. Zhang W, Narayanan M, Friedlander RM. Additive neuroprotective effects of minocycline with creatine in a mouse model of ALS. Ann Neurol 2003; 53:267-70.

12. Royes LFF, Fighera MR, Furian AF, Oliveira MS, Myskiw JdC, Fiorenza NG, et al Effectiveness of creatine monohydrate on seizures and oxidative damage induced by methylmalonate. Pharmacol Biochem Behav 2006; 83:136-44.

13. Lensman M, Korzhevskii DE, Mourovets VO, Kostkin VB, Izvarina N, Perasso L, et al. Intracerebroventricular administration of creatine protects against damage by global cerebral ischemia in rat. Brain Res 2006; 1114:187-94.

14. Prass K, Royl G, Lindauer U, Freyer D, Megow D, Dirnagl U, et al. Improved reperfusion and neuroprotection by creatine in a mouse model of stroke. J Cereb Blood Flow Metab 2007; 27:452-9.

15. Rakpongsiri K, Sawangkoon S. Protective effect of creatine supplementation and estrogen replacement on cardiac reserve function and antioxidant reservation against oxidative stress in exercise-trained ovariectomized hamsters. Int Heart J 2008; 49:343-54.

16. Mecocci P, Fano G, Fulle S, MacGarvey U, Shinobu L, Polidori MC, et al. Agedependent increases in oxidative damage to DNA, lipids and proteins in human skeletal muscle. Free Radic Biol Med 1999; 26:303-8.

17. Tarnopolsky MA, Safdar A. The potential benefits of creatine and conjugated linoleic acid as adjuncts to resistance training in older adults. Appl Physiol Nutr Metab 2008; 33:213-27.

18. Rodriguez MC, MacDonald JR, Mahoney DJ, Parise G, Beal MF, Tarnopolsky MA Beneficial effects of creatine, CoQ and lipoic acid in mitochondrial disorders. Muscle Nerve 2007; 35:235-42.

19. Tarnopolsky MA, Simon DK, Roy BD, Chorneyko K, Lowther SA, Johns DR, et al Attenuation of free radical production and paracrystalline inclusions by creatine supplementation in a patient with a novel cytochrome b mutation. Muscle Nerve 2004; 29:537-47.

20. Boveris A, Chance B. The mitochondrial generation of hydrogen peroxide. General properties and effect of hyperbaric oxygen. Biochem J 1973; 134:701-16.

21. Cooper C, Vollaard N, Choueiri T, Wilson M. Exercise, free radicals and oxidative stress. Biochem Soc Trans 2002; 30:280-5.

22. Ashton T, Young IS, Peters JR, Jones E, Jackson SK, Davies B, et al. Electron spin resonance spectroscopy, exercise and oxidative stress: an ascorbic acid intervention study. J Appl Physiol 1999; 87:2032-6.

23. Kingsley M, Wadsworth D, Kilduff LP, McEneny J, Benton D. Effects of phosphatidylserine on oxidative stress following intermittent running. Med Sci Sports Exerc 2005; 37:1300-6.

24. Aoi W, Naito Y, Takanami Y, Kawai Y, Sakuma K, Ichikawa H, et al. Oxidative stress and delayed-onset muscle damage after exercise. Free Rad Biol Med 2004; 37:480-7.

25. Kuethe F, Krack A, Richartz BM, Figulla HR. Creatine supplementation improves muscle strength in patients with congestive heart failure. Pharmazie 2006; 61:218-22.

26. Kilduff LP, Georgiades E, James N, Minnion RH, Mitchell M, Kingsmore D, et al. The effects of creatine supplementation on cardiovascular, metabolic and thermoregulatory responses during exercise in the heat in endurance-trained humans. Int J Sport Nutr Exerc Metab 2004; 14:443-60

27. Chwalbinska-Moneta J. Effect of creatine supplementation on aerobic performance and anaerobic capacity in elite rowers in the course of endurance training. Int J Sport Nutr Exerc Metab 2003; 13:173-83.

28. Stroud MA, Holliman D, Bell D, Green AL, Macdonald IA, Greenhaff PL. Effect of Oral Creatine Supplementation on Respiratory Gas-Exchange and Blood Lactate Accumulation During Steady-State Incremental Treadmill Exercise and Recovery in Man. Clin Sci 1994; 87:707-10.

29. Zoeller RF, Stout JR, O'Kroy JA, Torok DJ, Mielke M. Effects of 28 days of beta-alanine and creatine monohydrate supplementation on aerobic power, ventilatory and lactate thresholds, and time to exhaustion. Amino Acids 2007; 33:505-10.

30. Canete S, San Juan AF, Perez M, Gomez-Gallego F, Lopez-Mojares LM, Earnest CP, et al Does creatine supplementation improve functional capacity in elderly women? J Strength Cond Res 2006; 20:22-8.

31. Murphy AJ, Watsford ML, Coutts AJ, Richards DAB. Effects of creatine supplementation on aerobic power and cardiovascular structure and function. J Sci Med Sport 2005; 8:305-13.

32. Fuld JP, Kilduff LP, Neder JA, Pitsiladis Y, Lean MEJ, Ward SA, et al. Creatine supplementation during pulmonary rehabilitation in chronic obstructive pulmonary disease. Thorax 2005; 60:531-7. 
33. Deacon SJ, Vincent EE, Greenhaff PL, Fox J, Steiner MC, Singh SJ, et al. Randomized controlled trial of dietary creatine as an adjunct therapy to physical training in chronic obstructive pulmonary disease. Am J Respir Crit Care Med 2008; 178:233-9.

34. O'Reilly DS, Carter R, Bell E, Hinnie J, Galloway PJ. Exercise to exhaustion in the second-wind phase of exercise in a case of McArdle's Disease with and without creatine supplementation. Scott Med J 2003; 48:46-8.

35. Stout JR, Graves BS, Cramer JT, Goldstein ER, Costa PB, Smith AE, et al. Effects of creatine supplementation on the onset of neuromuscular fatigue threshold and muscle strength in elderly men and women (64-86 years). J Nutr Health Aging 2007; 11:459-64.

36. Rawson E, Persky A, Price T, Clarkson P. Effects of repeated creatine supplementation on muscle, plasma and urine creatine levels. J Strength Cond Res 2004; 18:162-7.

37. Kingsley M, Miller M, Kilduff LP, McEneny J, Benton D. Effects of phosphatidylserine on exercise capacity during intermittent exercise in active males. Med Sci Sports Exerc 2006; 38:64-71.

38. Andrews R, Greenhaff P, Curtis S, Perry A, Cowley AJ. The effect of dietary creatine supplementation on skeletal muscle metabolism in congestive heart failure. Eur Heart J 1998; 19:617-22.

39. Verbessem P, Lemiere J, Eijnde BO, Swinnen S, Vanhees L, Van Leemputte M, et al. Creatine supplementation in Huntington's disease: A placebo-controlled pilot trial. Neurology 2003; 61:925-30.

40. Bender A, Koch W, Elstner M, Schombacher Y, Bender J, Moeschl M, et al. Creatine supplementation in Parkinson disease: A placebo-controlled randomized pilot trial. Neurology 2006; 67:1262-4.

41. Hass CJ, Collins MA, Juncos JL. Resistance Training With Creatine Monohydrate Improves Upper-Body Strength in Patients With Parkinson Disease: A Randomized Trial. Neurorehabil Neural Repair 2007; 21:107-15.

42. Bender A, Samtleben W, Elstner M, Klopstock T. Long-term creatine supplementation is safe in aged patients with Parkinson disease. Nutr Res 2008; 28:172-8.

43. Groeneveld GJ, Veldink JH, Tweel Ivd, Kalmijn S, Beijer C, de Visser M, et al. A randomized sequential trial of creatine in amyotrophic lateral sclerosis. Ann Neurol 2003; 53:437-45.

44. Mazzini L, Balzarini C, Colombo R, Mora G, Pastore I, De Ambrogio R, et al. Effects of creatine supplementation on exercise performance and muscular strength in amyotrophic lateral sclerosis: preliminary results. J Neurol Sci 2001; 191:139-44.

45. Shefner JM, Cudkowicz ME, Schoenfeld D, Conrad T, Taft J, Chilton M, et al. A clinical trial of creatine in ALS. Neurology 2004; 63:1656-61.

46. Willer B, Stucki G, Hoppeler H, Bruhlmann P, Krahenbuhl S. Effects of creatine supplementation on muscle weakness in patients with rheumatoid arthritis. Rheumatology 2000; 39:293-8.

47. Fuld JP, Kilduff LP, Neder JA, Pitsiladis Y, Lean MEJ, Ward SA, et al. Creatine supplementation during pulmonary rehabilitation in chronic obstructive pulmonary disease. Thorax 2005; 60:531-7.

48. Kilduff LP, Lewis S, Kingsley M, Owen NJ, Dietzig RE. Reliability and detecting change following short-term creatine supplementation: comparison of two-component body composition methods. J Strength Cond Res 2007; 21:378-84.

49. Dill DB, Costill DL. Calculation of percentage changes in volumes of blood, plasma and red cells in dehydration. J Appl Physiol 1974; 37:247-8.

50. McEneny J, Trimble ER, Young IS. A simple method for assessing copper-mediated oxidation of very-low-density lipoprotein isolated by rapid ultracentrifugation. Ann Clin Biochem 1998; 35:504-14.

51. McDowell IF, McEneny J, Trimble ER. A rapid method for measurement of the susceptibility to oxidation of low-density lipoprotein. Ann Clin Biochem 1995; 32:167-74.

52. Esterbauer H, Striegl G, Puhl H, Rotheneder M. Continuous monitoring of in vitro oxidation of human low density lipoprotein. Free Radic Res Commun 1989; 6:67-75.

53. Vuilleumier JP, Keck E. Fluorimetric assay of vitamin C in biological materials using a centrifugal analyser with fluorescence attachment. J Micronutrient Anal 1993; 5:25-34

54. Craft NE. Carotenoid reversed-phase high-performance liquid chromatography methods. Methods in Enzymology. Academic Press 1992. 


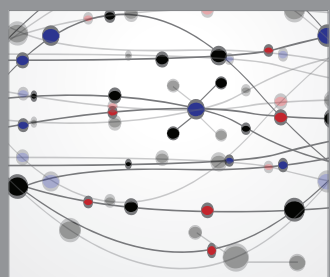

The Scientific World Journal
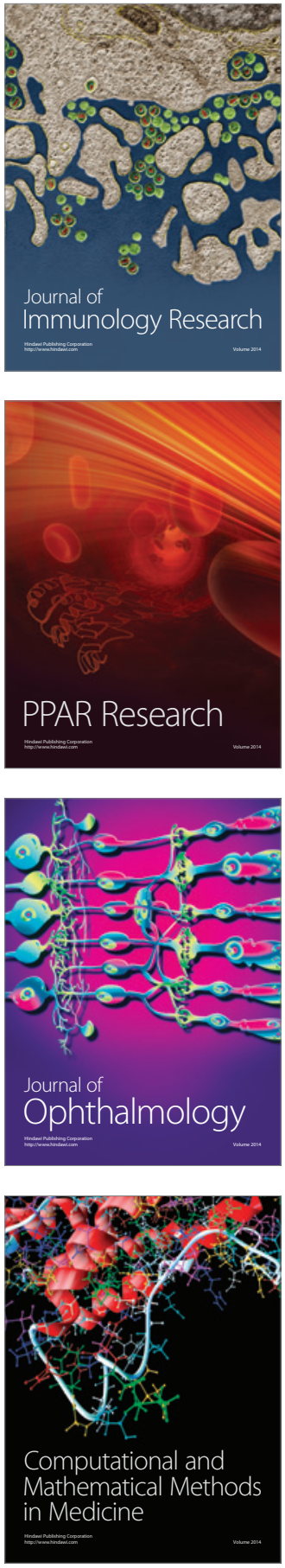

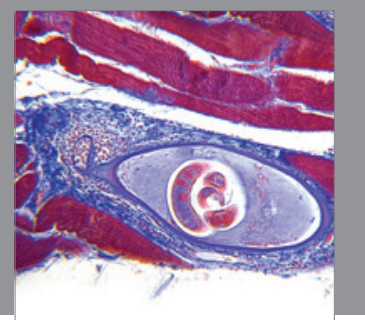

Gastroenterology

Research and Practice
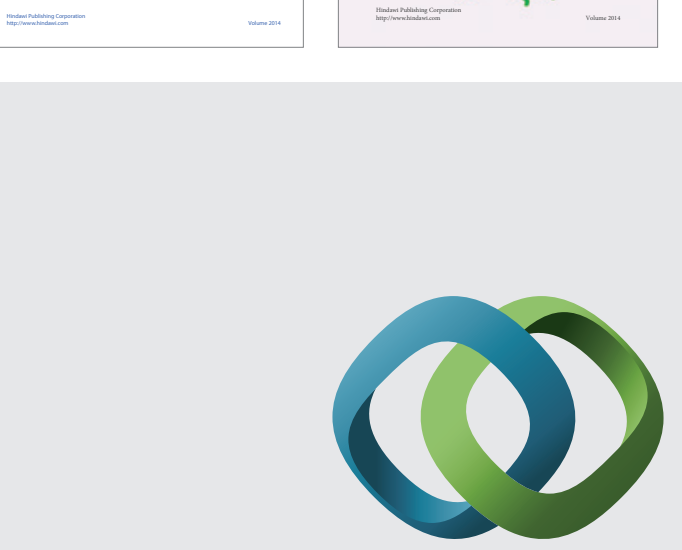

\section{Hindawi}

Submit your manuscripts at

http://www.hindawi.com
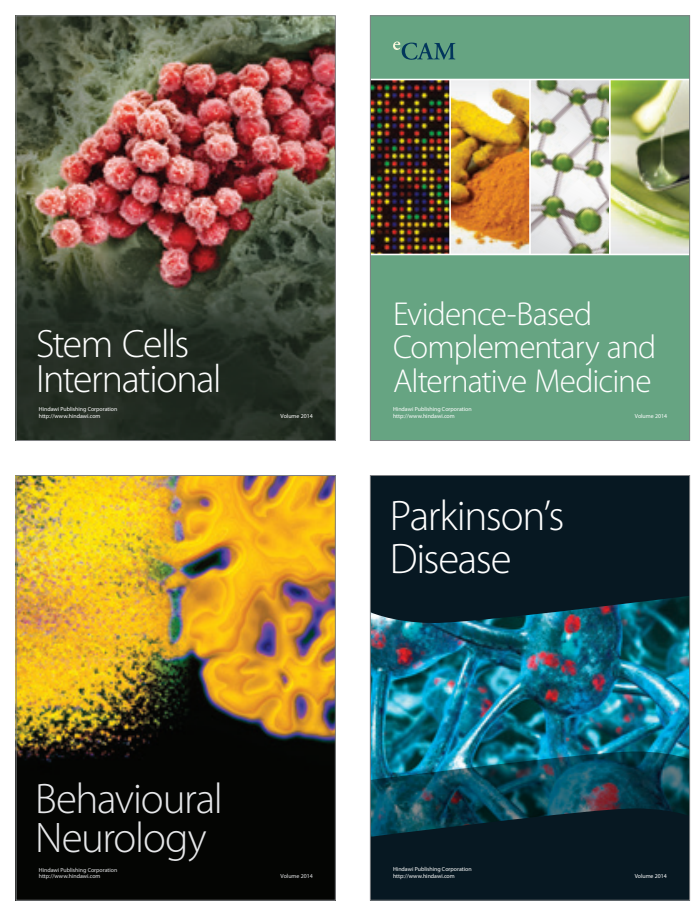

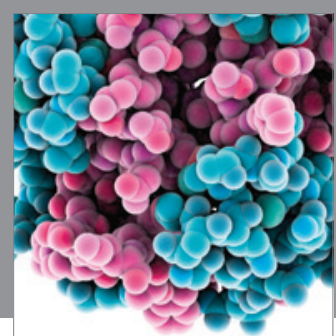

Journal of
Diabetes Research

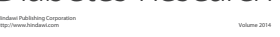

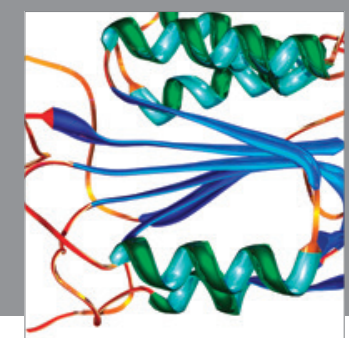

Disease Markers
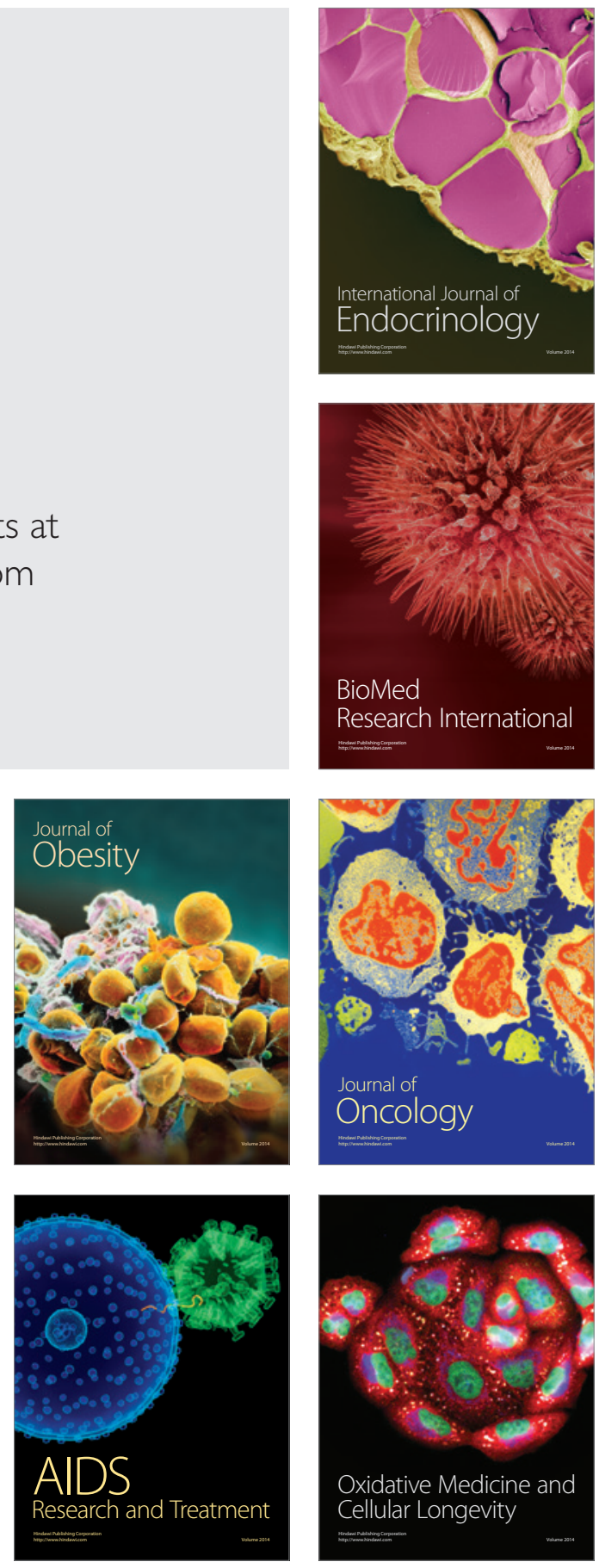